\title{
A CASE OF STURGE-WEBER SYNDROME
}

\author{
Daniela Trasca1, Vlad Claudiu Stefanescu', Inimioara Mihaela Cojocaru, ${ }^{1,2}$ \\ ${ }^{1}$ Neurology Department, „Colentina“ Clinical Hospital, Bucharest \\ ${ }^{2}$ „Carol Davila“ University of Medicine and Pharmacy, Bucharest
}

\begin{abstract}
Encephalo-trigeminal angiomatosis of Sturge-Weber-Krabbe-Dimitri is a rare hereditary sporadic facomatosis, characterized by the presence of angiomatosis of brain lining vessels, face and eye capillaries. We present the case of a 25-year old girl with a birth mark, an facial angioma localized in the territory of the right ophthalmic nerve, also since she had 4 months, she presents generalized tonic-clonic seizures, for which she is currently under treatment with Levetiracetam 1000 mg/day, Lamotrigine 100 mg/day, Valproic Acid 1500 mg/day and Clonazepam $2 \mathrm{mg} /$ day. She was hospitalized because of the higher incidence of the seizures, despite the treatment that she performs. Physical examination revealed her facial angioma, a facial dysmorphism, gingival hypertrophy with sharp teeth, and she has an upper limb asymmetrical development. The neurological exam reveals central facial paresis, a rough motor deficit on her left side, increased tendon reflexes on the left side, left limb ataxia, and a minor cognitive disorder. The cerebral CT identified cortical asymmetry with right frontal atrophy, gyriform calcifications and frontal hyperostosis. The brain MRI showed hemihypotrophia of the right cerebral hemisphere, especially regarding the frontal lobe, gyriform calcifications on the right side, hypertrophy of the right frontal sinus. We increased the dosage of antiepileptic drugs, to $1500 \mathrm{mg} /$ day of Levetiracetam and $200 \mathrm{mg} /$ day of Lamotrigine. The outcome was favorable, the patient was seizures-free. The particularity of the case is that being a rare disease, it is easily overlooked, although the patient had classic symptoms and imagistic findings for Sturge-Weber-Krabbe disease.
\end{abstract}

Keywords: Encephalo-trigeminal angiomatosis, Sturge-Weber syndrome, seizures

\section{INTRODUCTION}

Encephalo-trigeminal angiomatosis of SturgeWeber-Krabbe-Dimitri is a rare hereditary sporadic facomatosis, characterized by the presence of angiomatosis of brain lining vessels, face and eye capillaries with a frequency of 1 in 50000 pregnancies (1).

This neurocutaneous syndrome manifests with vascular malformations resulting from the failure of fetal veins to develop normally in the brain, skin, and eye. These abnormalities lead to venous hypertension and subsequent hypoperfusion of the underlying cortex causing chronic cerebral ischemia, atrophy, and neurological deterioration. SturgeWeber syndrome causes physical, psychological, and social disorders and it occurs with equal fre- quency in both sexes, with seizures typically developing in the first year of life .The classic symptoms triad: facial angiomatosis, brain lining angiomatosis, glaucoma and convulsions, are present in $20 \%$ of cases, usually are noted mono- and bi-symptom forms of this disease (2).

Sturge Weber Syndrome (SWS) is referred to as complete when both CNS and facial angiomas are present, and incomplete when only the face or CNS is affected. According to Roach classification there are 3 basic forms of encephalotrigeminal angiomatosis:

- Type I-Facial and leptomeningeal angiomas; patient may have glaucoma

- Type II-Facial angioma alone (no CNS involvement); patient may have glaucoma

- Type III-Isolated leptomeningeal angiomas; usually no glaucoma (3) 
The neurologic manifestations of SWS vary, depending on the location of the leptomeningeal angiomatosis (which most commonly are located in the parietal and occipital regions) and the secondary effects of the angiomas. These neurologic morbidities may include besides seizures - which can be intractable, focal deficits-including hemiparesis and hemianopsia, both of which may be transient (called "stroke-like episodes"), headaches, developmental disorders-including developmental delay, learning disorders, and intellectual disability; Focal or generalized motor seizures usually begin in the first year of life. Profound seizure activity sometimes may be observed, with resultant further neurologic and developmental deterioration. Seizure control is thought to improve the neurologic outcome, and epilepsy surgery may be beneficial for refractory seizures (4).

Encephalo-trigeminal angiomatosis treatment is symptomatic, using anticonvulsive, neuroprotecting preparations and medicines that decrease intracranial and intraocular pressure. It may be also taken into consideration laser therapy regarding the port wine stain; and in the case of epileptic seizures resistance, neurosurgical interventions are applied, such as hemispherectomy, focal cortical resection or vagus nerve stimulation (5-7).

\section{CASE PRESENTATION}

We present the case of a 25 year old girl with a birth mark, an facial angioma localized in the territory of the ophthalmic branch of the right trigeminal nerve, also since she had 4 months, she presents generalized tonic-clonic seizures, for which she is currently under treatment with Levetiracetam $1000 \mathrm{mg} /$ day, Lamotrigine $100 \mathrm{mg} /$ day, Valproic Acid $1500 \mathrm{mg}$ /day and Clonazepam $2 \mathrm{mg}$ /day. She was hospitalized into our clinic to evaluate her treatment because of the higher incidence of the seizures, despite the treatment that she performs.

Physical examination revealed her facial angioma in the territory of the ophthalmic branch on the right trigeminal nerve, also called "nevus flammeus" or "the port-wine stain", a facial dysmorphism, gingival hypertrophy with sharp teeth, and she has an upper limb asymmetrical development, hypotrophia of her left upper limb (Fig. 1, Fig. 2, and Fig. 3).

The neurological exam reveals central facial paresis, a rough motor deficit on her left side, increased tendon reflexes on the left side, with plantar cutaneus reflex in flexion, limb ataxia, and a minor cognitive disorder.

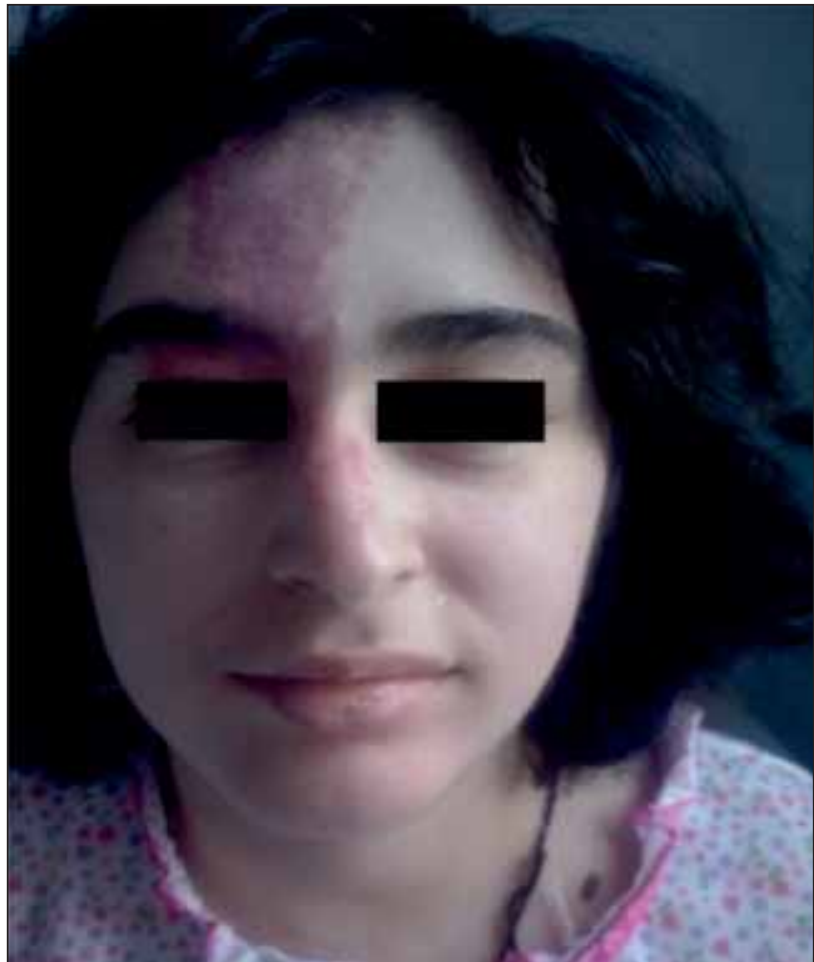

FIGURE 1. Nevus flammeus situated on the patient's forehead upper right eyelid and nose

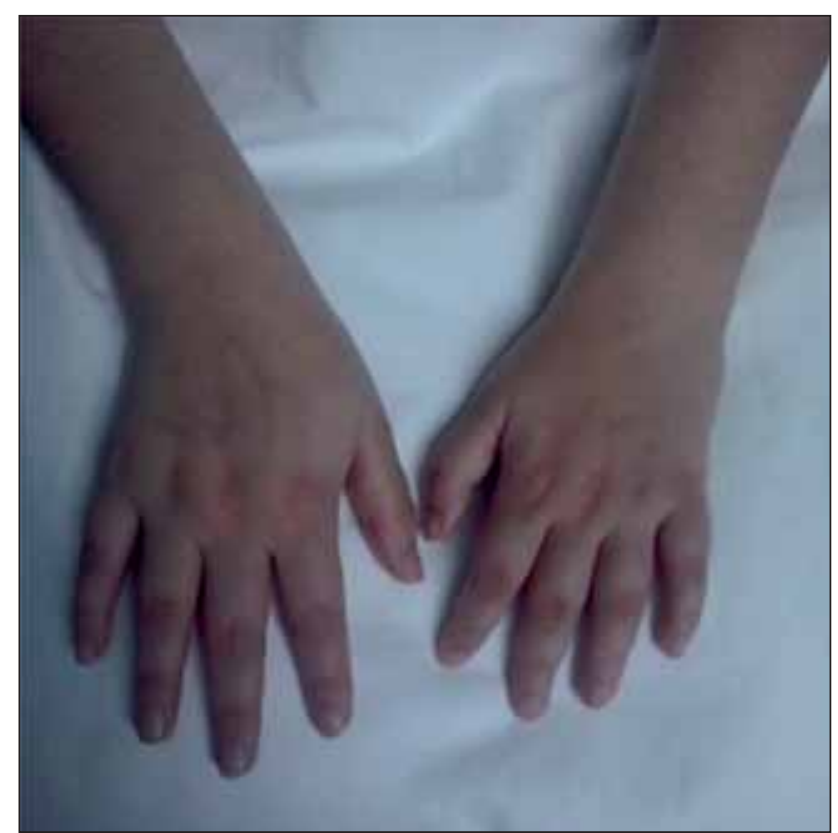

FIGURE 2. Upper limb asymmetrical development, hypotrophia of her left upper limb

The first step was to increase the dosage of antiepileptic drugs, to $1500 \mathrm{mg} /$ day of Levetiracetam and $200 \mathrm{mg} /$ day of Lamotrigine, and then we performed other investigations.

We performed an EEG that didn't reveal any discharges (Fig. 4), and the next step was to perform an cerebral CT which identified cortical asymmetry with right frontal atrophy, gyriform calcifications and frontal hyperostosis (Fig. 5). 


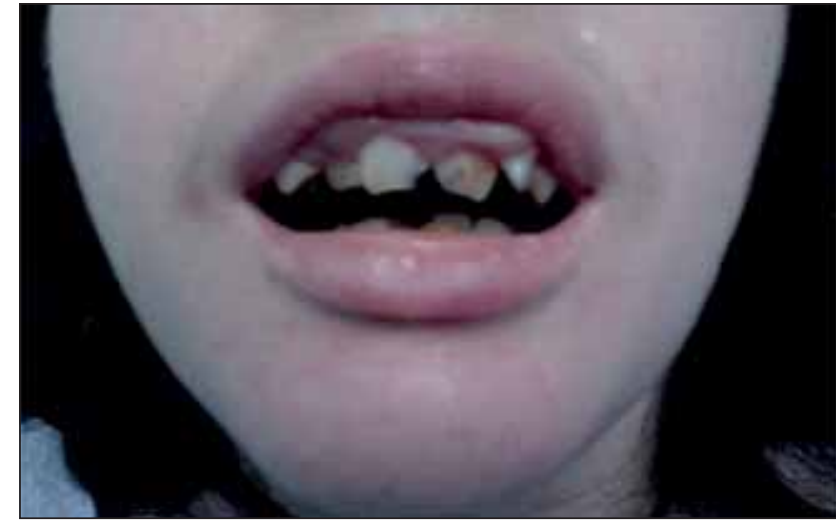

FIGURE 3. Facial dysmorphism, gingival hypertrophy with sharp teeth

The brain MRI (Fig. 6) showed hemihypotrophia of the right cerebral hemisphere, especially regarding the frontal lobe, gyriform calcifications on the right side, clearly visible on $\mathrm{T} 2$ sequence, hypertrophy of the right frontal sinus.
Ophthalmologic examination didn`t reveal significant changes, and the visual potentials were normal.

Considering the final results of our tests and the clinical exam, our patient was diagnosed with Sturge-Weber disease and further receives antiepileptic treatment.

\section{DISCUSSION}

The patient was a 25-year old female who was previously diagnosed with infant encephalopathy with tonic-clonic seizures and received anticonvulsivant therapy. She was admitted into our hospital for an increase in the seizures frequency and during her time in the hospital the symptoms were put together and the diagnosis of Sturge-Weber disease emerged.

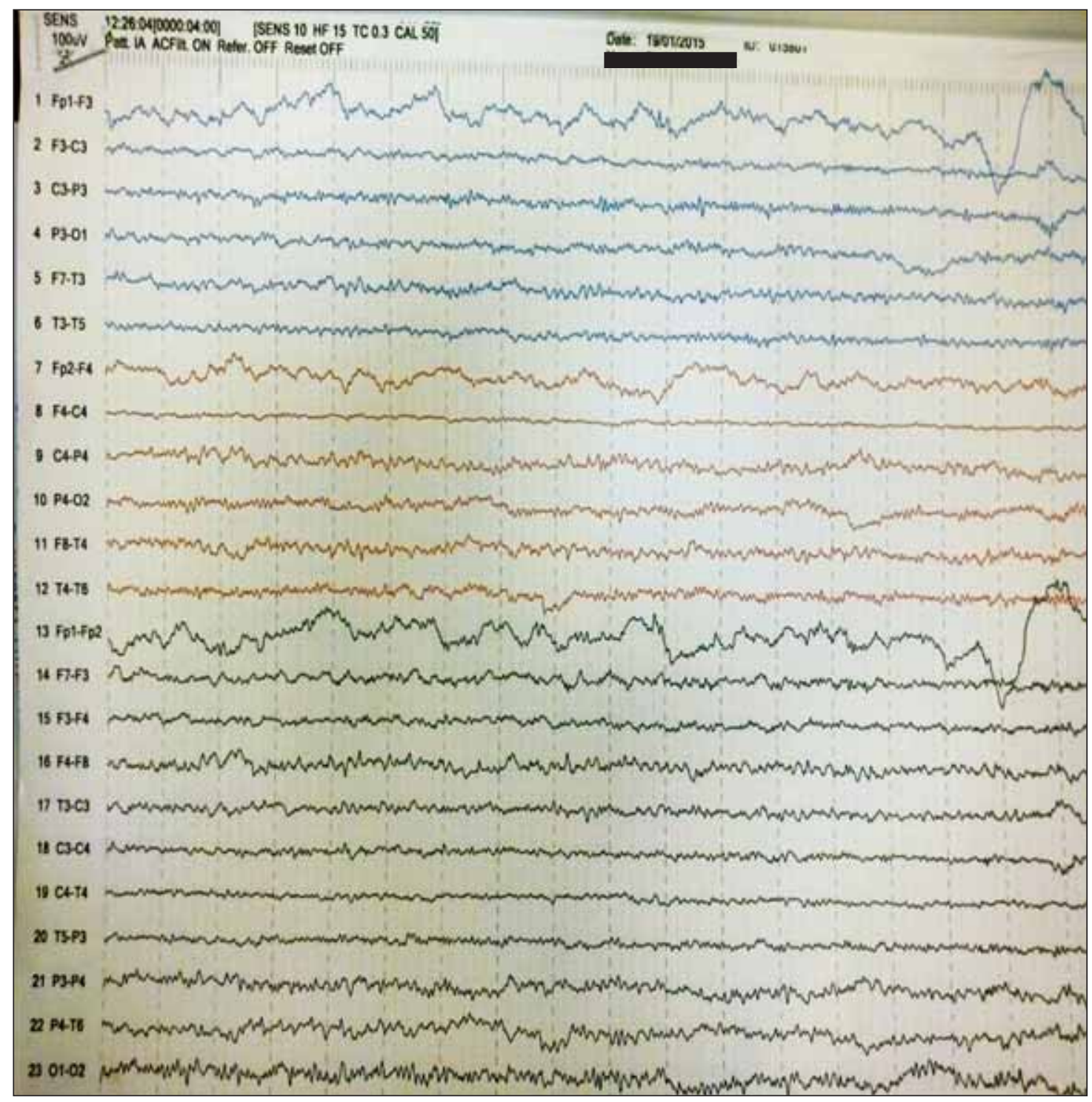

FIGURE 4. EEG showing no paroxystic electric activity 

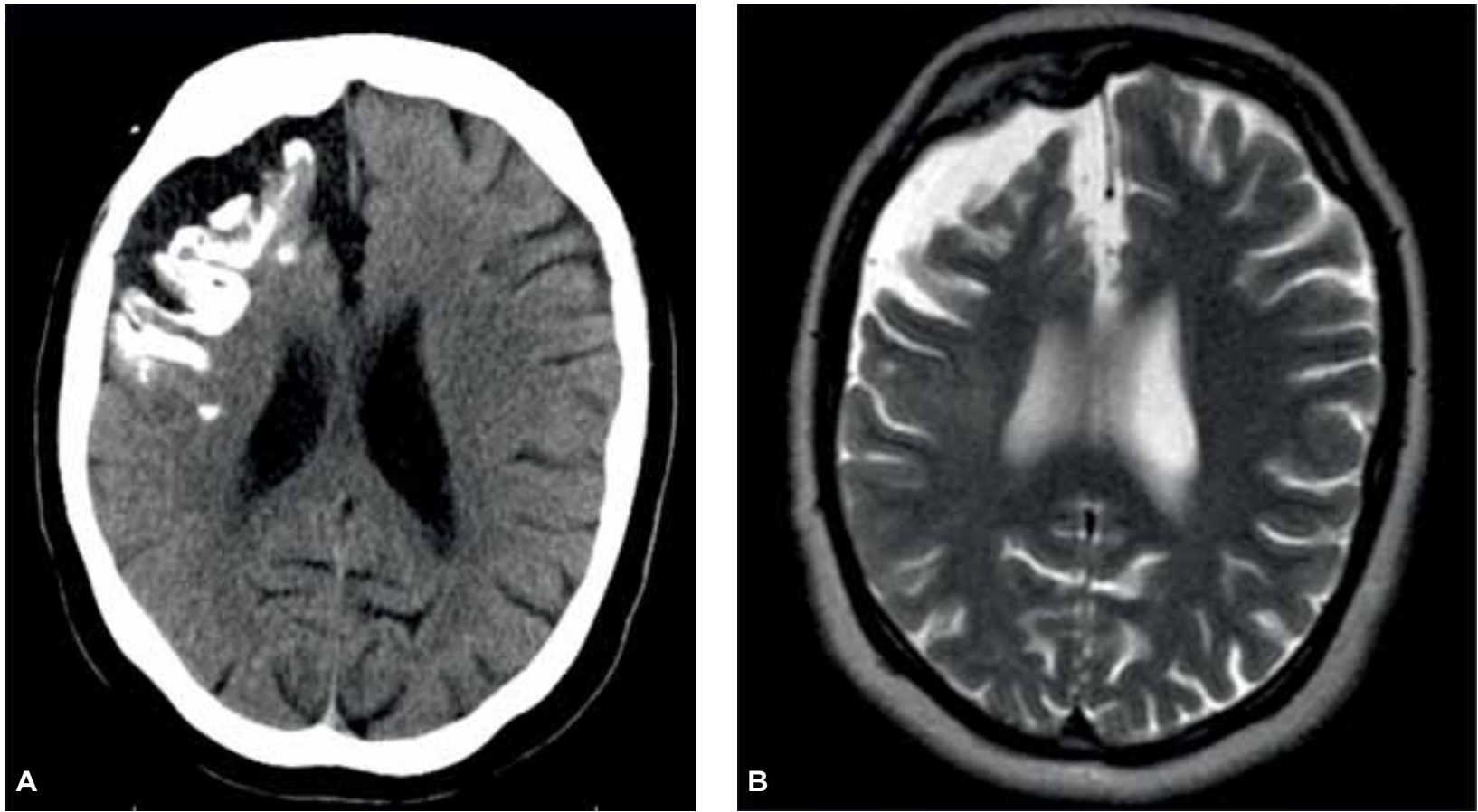

FIGURE 5 and FIGURE 6. Cerebral CT $(A)$ and MRI $(B)$ images showing right frontal lobe atrophy, gyriform calcifications and frontal hyperostosis

This condition is a rare, genetic-related disease, due to a mutation in the genes responsible for the regulation of the structure and function of blood vessels, innervation of blood-vessels, and expression of extracellular matrix and vasoactive molecules (8). Only two mutations were noted, one in chromosome 4q, the other was trisomy 10 (9).

Sturge-Weber syndrome is caused by residual embryonal vessels and their secondary effects on surrounding brain-tissue. Normally during fetal development, in the sixth week, a vascular plexus develops around the cephalic portion of the neural tube, under the ectoderm destined to become the facial skin, which regresses in the ninth week. Failure of this normal regression results in residual vascular tissue, which forms the angiomata of the leptomeninges, face, and ipsilateral eye (10).

Effects of the surrounding brain tissue include hypoxia, ischemia, venous occlusion, trombosis, infarction (11-12).

From a review of pathologic specimens, Norman and Schoene thought that blood flow abnormalities in the leptomeningeal angiomas caused increased capillary permeability, stasis, and anoxia (13). Garcia et al and Gomez and Bebin reported that venous occlusion may actually cause the initial neurologic event, either a seizure, transient hemiparesis, or both, thereby beginning the process $(14,15)$.

A "vascular steal phenomenon" may develop around the angioma, resulting in cortical ischemia. Recurrent seizures, status epilepticus, intractable seizures, and recurrent vascular events may aggravate this steal further, with an increase in cortical ischemia, resulting in progressive calcification, gliosis, and atrophy - the patient presented apart from naevus flammeus right frontal atrophy, which in turn increase the chance of seizures and neurologic deterioration. $(16,17)$.

\section{CONCLUSIONS}

The particularity of the case is that being a rare disease, it is easily overlooked, although the patient had classic symptoms and imagistic findings for Sturge-Weber-Krabbe disease. 


\section{REFERENCES}

1. Ruggieri M., Castroviejo I.P., Di Rocco C. Neurocutaneous Disorders: Phakomatoses and Hamartoneoplastic Syndromes. Springer Verlag Wien 2008; 1070

2. Bodensteiner J.B., Roach E.S. In:Sturge-Weber Syndrome. Bodensteiner JB, Roach ES, editor. Sturge-Weber Foundation, Mt. Freedom, NJ 1999; Sturge-Weber syndrome: Introduction and overview:1-10

3. Roach E.S. Neurocutaneous syndromes. Pediatr Clin North Am. 1992; 39: 591-620

4. American Association of Neuroscience Nurses. Care of the patient with seizures. $2^{\text {nd }}$ ed. Glenview (IL) 2007

5. Hoffman H.J. Benefits of early surgery in Sturge Weber syndrome. In: Tuxhorn I, Holthausen H., Boenigk H., eds. Paediatric Epilepsy syndromes and their surgical treatment. London: John Libbey and Company 1997: 364-370

6. Holmes G.L. Surgery for intractable seizures in infancy and early childhood. Neurology 1993; 43: S28-37

7. Bruce D.A. Neurosurgical aspects in Sturge Weber Syndrome. Bodensteiner J.B., Roach E.S. Sturge Weber Syndrome. Mt Freedom, NJ:Sturge Weber foundation; 1999: 39-42

8. Takeoka M., Rivello Jr J.J. Sturge-Weber Syndrome [Internet]. [Place unknown]: Medscape; 2015 [updated 2013 May 20; cited 2015 Feb 27]. Available from: http://emedicine.medscape.com/ article/1177523-overview
9. Cunha ESÃ M., Barroso C.P., Caldas M.C. Innervation pattern of malformative cortical vessels in Sturge-Weber disease: an histochemical, immunohistochemical, and ultrastructural study. Neurosurgery 1997; 41: 872-6; discussion 876-7.

10. Rochkind S., Hoffman H.J., Hendrick E.B. Sturge-Weber Syndrome: Natural history and prognosis. J Epilepsy 1990; 3 (Suppl): 293-304

11. Comi A.M. Advances in Sturge-Weber syndrome. Curr Opin Neurol. 2006; 19:124-8

12. Comi A.M. Pathophysiology of Sturge-Weber syndrome. J Child Neurol 2003; 18: 509-16

13. Norma N.M.G., Schoene W.C. The ultrastructure of Sturge-Weber disease. Acta Neuropathol (Berl). 1977; 37: 199-205

14. Garcia J.C., Roach E.S., McLean W.T. Recurrent thrombotic deterioration in the Sturge-Weber syndrome. Childs Brain. 1981; 8: 427-33

15. Gomez M.R., Bebin E.M. Sturge-Weber syndrome. In: Butterworths B. Neurocutaneous Diseases: A Practical Approach. 1987: 356-367

16. Aylett S.E., Neville B.G., Cross J.H. Sturge-Weber syndrome: cerebral haemodynamics during seizure activity. Dev Med Child Neurol. 1999; 41:480-5

17. Okudaira Y., Arai H., Sato K. Hemodynamic compromise as a factor in clinical progression of Sturge- Weber syndrome. Childs Nerv Syst. 1997; 13:214-9 